\title{
Aspectos de carácter elegíaco en el Tirant lo Blanch
}

\author{
SONIA GROS Lladós
}

El objetivo de este artículo es analizar algunos de los motivos amatorios característicos de la elegía latina cuyo rastro es perceptible en el Tirant lo Blanch, no tanto desde la perspectiva de una influencia directa, sino desde la continuidad cultural de siglos de tradición literaria más o menos oculta, así como de la nueva sensibilidad literaria propia del período en que se escribe esta novela.

Los estudiosos de las fuentes de Joanot Martorell están hoy en día de acuerdo en señalar su desconocimiento de la lengua latina y, con ello, de los textos literarios latinos en versión original. En cambio, es innegable en su obra la importancia de la huella de algunos de los grandes autores clásicos — Séneca y Ovidio, fundamentalmente- a partir de autores como Boccaccio o de las traducciones catalanas de sus obras. En este trabajo se intentará examinar la presencia de rasgos propios del género elegíaco latino presentes en la novela catalana y su tratamiento por parte del autor. Considerando que la influencia de Ovidio es ampliamente conocida y ha sido estudiada en profundidad, (HAUF, 1993), el análisis se centrará preferentemente en la obra de los otros representantes del género en la literatura latina - Catulo, Tibulo, Propercio- a sabiendas de que su influencia directa debe ser descartada. El propósito de este artículo, por tanto, es comparar el tratamiento de motivos comunes presentes en la tradición literaria de la que bebe Martorell y que se remontan en último término a los poetas latinos citados.

En una obra de tan enorme complejidad, el amor constituye uno de los elementos con mayor peso. Un amor que se presenta en su perspectiva más lúdica y sensual, pero también realista e incluso, en el desenlace final, con tonos marcadamente trágicos, es decir, desde una pluralidad de perspectivas. Todo lo cual, como veremos, se encontraba ya en los poetas eróticos latinos. En efecto, la lectura atenta de los versos de los elegíacos latinos desvela numerosos puntos en común con la novela del escritor valenciano. En este estudio se abordarán tan sólo algunos de los principales tópicos de la elegía amatoria: la militia amoris, la idea del amor como una esclavitud, la imagen de la amada, las señales amorosas y el poder del amor. 


\section{RISIT AMOR}

La sensualidad del amor en el Tirant ha sido puesta de relieve de forma general por los especialistas dedicados al estudio de la novela. Ya Martí de Riquer la calificó como «novel-la de jocs d'amor i d'alegria» (RIQUER, 1990) y se ha señalado repetidamente su tratamiento novedoso del amor, su humorismo y vitalismo «imprescindibles per a entendre la fina ironia de tota la dialèctica amorosa del Tirant i, en especial, l'esperit lúdic i sensual desplegat al llarg de l'obra» (ALPERA, 1987). Se ha subrayado su erotismo e, incluso, su obscenidad, impensables en otras obras de la tradición caballeresca, como características de la originalidad de la obra en el marco de su tradición literaria (CACHO BLECUA, 1993). Sin embargo, el Tirant es mucho más que una obra caballeresca, y todos estos aspectos novedosos se encuentran ya en la tradición literaria amatoria de origen latino en la que se inserta, asimismo, la novela ${ }^{1}$.

Es, en efecto, Ovidio, el modelo amatorio más significativo de Martorell ${ }^{2}$, quien muestra precisamente esta imagen festiva y ligera de Amor — quizás no en las Heroidas, pero sin duda en sus obras más propiamente elegíacas-, un dios que hiere y que, al mismo tiempo, ríe y juega:

Antes, en cambio, yo tenía miedo de la noche y los vanos fantasmas; me admiraba de que alguien pudiera andar en medio de tinieblas. Entonces Cupido, a la vera de su tierna madre, se rió de forma que yo lo oyera y me dijo en voz baja: «Tú también llegarás a ser valiente.» (Amores, I, 6, 9-11)

La jocosidad, la ironía y la frivolidad prestan a la poesía amorosa de Ovidio una gracia especial, sus versos recrean una atmósfera alegre y divertida en la que, frente a otros elegíacos, prima el goce del amor sobre cualquier otra preocupación más seria. Y esta es precisamente la misma atmósfera que domina en la corte de Constantinopla en toda la sección central de la novela. Insinuaciones y juegos amorosos, bailes y banquetes, misivas y regalos entretienen a los protagonistas de la novela. No son Tirant y Carmesina, ni mucho menos, los únicos ocupados en el amor. A las aventuras amorosas de la pareja paralela, Diafebus y Estefanía, se suman las relaciones de la emperatriz e Hipòlit, los escarceos del emperador con Plaerdemavida, el interés de esta última por Hipòlit, o las intrigas de la Viuda Reposada. Los intereses amorosos se imponen a cualquier otro tipo de preocupaciones, aspecto sumamente llamativo considerando la situación crítica que se supone que está atravesando el Imperio griego en la novela.

Como en la obra de Martorell, Ovidio no ahorra detalles concretos sobre el acto amoroso (Ars, II, v. 703ss), o la manera de conseguir el placer sexual, en es-

${ }^{1}$ Consideración que ha sido subrayada por algunos de los especialistas en la obra. Tal como Badia señala: «El text del Tirant és un terreny d'hibridacions i convergències de molts materials diversos, la majoria dels quals són patrimoni comú dels escriptors del segle XV català» (BADIA, 1993, p. 81).

2 En sus estudios sobre la influencia de las Heroidas en Martorell, Hauf destaca en la novela «la volguda i deliberada assimilació de textos ovidians» (HAUF, 1993, p. 397), convertidos en modelo sentimental de la prosa vulgar contemporánea. 
cenas de un fuerte contenido erótico. La búsqueda del goce amoroso es para el poeta latino el propósito principal del amante:

Pero a mí, tóqueme en suerte languidecer en el movimiento de Venus; cuando me muera, apáguese mi vida en medio del acto amoroso; y que alguien llorando diga en mi funeral: «Esta muerte ha sido acorde con tu vida». (Amores, II, 10, 35-39)

Deseo que recuerda lejanamente las palabras de Plaerdemavida dirigidas a Tirant en la célebre escena del baño de Carmesina:

Mira, Tirant, vet ací lo seu ventre, les cuixes e lo secret. ¡Oh trista de mi, que si home fos, ací voldria finir los meus darrers dies! (MARTORELL, J. Tirant lo Blanch, Cap. 231)

El propio Ovidio es citado expresamente como autoridad en materia amorosa repetidas veces a lo largo de la obra:

Certament jo crec — dix la infanta— que vós aveu aprés en la escola de honor, lla on se lig de aquell famós poeta Ovidi, lo qual en tots sos llibres ha parlat tostemps de amor verdadera. E qui fa son poder de emitar al mestre de la sciència, no fa poch. (cap. 119)

no sólo por los amantes Tirant y Carmesina, sino también por otros personajes de la obra, como el fraile que oficia la misa después del matrimonio de Estefanía y Diafebus:

Diu Ovidi que lo major bé d'aquest món és amor (cap. 221)

O incluso por el emperador en su lamento por el trágico final de Tirant:

Muira jo e iré als regnes de Plutó, de tanta dolor portant ambaixada; faré que Ovidi del meu Tirant digníssims versos esmalte. (cap. 472)

\section{MILITAT OMNIS AMANS}

En la expresión de los sentimientos amorosos de los personajes del Tirant es particularmente frecuente la presencia de metáforas y léxico del mundo militar aplicados a las relaciones amorosas. El llamado militia amoris es un concepto originario de la poesía clásica, desarrollado ampliamente por los poetas elegíacos latinos. ${ }^{3}$ Ovidio estableció un detallado paralelismo entre la actividad del soldado y la del amante en una conocida elegía:

${ }^{3}$ La metáfora será, asimismo, ampliamente utilizada en la poesía medieval. La influencia de Ovidio es, por ejemplo, manifiesta en el asalto al castillo donde se guarda la rose vermeille en el Roman de la Rose. 
Es soldado todo amante y Cupido tiene su propio campamento. Ático, créeme, es soldado todo amante. La edad idónea para la guerra, conviene también para el amor. Cosa inútil es un soldado viejo, cosa inútil es el amor de un viejo. (Amores, I, 9, 1-4)

Pero el motivo había sido explotado en toda su amplitud por los poetas elegíacos anteriores, que precisamente rechazaban la milicia como forma de vida oponiéndola a su ideal de vida privada, nequitia, consagrada a la amada y alejada del foro o la vida del ejército:

Deja que yo, a quien la Fortuna siempre quiso ver postrado, dedique esta vida al amor hasta el final.

Muchos perecieron con gusto en un amor duradero, en cuyo número me cubra también la tierra.

Yo no he nacido para la gloria ni sirvo para las armas:

el destino quiere que yo me aliste en esta milicia.

$$
\text { (Propercio, Elegías, I, 6, 25-30) }
$$

No es este evidentemente el caso del caballero Tirant, capitán de las tropas del Imperio griego, conquistador de la Barbaria y salvador de Constantinopla, con la salvedad, como antes apuntábamos, de que en una parte de la novela encontramos tanto a Tirant como a sus principales compañeros de armas —Diafebus, Hipòlit—, consagrados exclusivamente a sus damas y alejados, por un tiempo al menos, de sus ocupaciones militares.

La militia amoris fue desarrollada en toda su amplitud en la elegía latina, en una transposición detallada de los diferentes aspectos de la vida militar a las relaciones amorosas con la amada. Es habitual la referencia al acto amoroso como el combate, la lucha o la batalla _proelium, bellum-:

el soldado cuenta las heridas, el pastor las ovejas;

Yo por el contrario, me ejercito en combates en angosto lecho:

cada cual pase el día en el arte de que es capaz.

(Propercio, Elegías, II, 1, 44-46)

Amor es un dios de paz, a la paz veneramos los enamorados:

duras son solo las batallas que sostengo con mi dueña.

$$
\text { (Elegías, III, 5, 1-2) }
$$

O como en el ejemplo del mito, así se nos dice de Paris:

Mientras vencen los dánaos, mientras resiste el troyano Héctor, él sostiene las mayores batallas en el regazo de Helena.

$$
\text { (Elegías, III, 8, 31-32) }
$$

Tal como hace Plaerdemavida cuando se dirige a Estefanía después de su noche de bodas:

Par-me que ja us és passada la dolor i la major pressa de la batalla. (cap. 220) 
O cuando alecciona abiertamente a Tirant sobre cómo debe comportarse con la Princesa:

anau a la sua cambra e gitau-vos en lo llit com ella hi sia nua o en camisa, e feriu valentment, que entre amics no hi cal tovalla. (cap. 229)

y de nuevo de forma insistente:

Cavaller gloriós, despullau-vos en camisa e descalç anau-vos a posar al costat d'aquella qui us ama més que a la sua vida; e feriu fort dels esperons, car així es pertany de cavaller, tota pietat a part posada. (cap. 434)

Las heridas provocadas por el amor están también presentes en los versos de los elegíacos romanos, ya sean reales:

Vean mis amigos heridas de mordiscos en mi cuello:

las moraduras muestren que he poseído a mi amada.

(Propercio, Elegías, III, 8, 21-22)

o metafóricas:

pues hiere antes de que a salvo veamos al enemigo

y nadie se marcha indemne de aquella herida.

(Elegías, II, 12, 11-12)

Sin embargo, a diferencia de la novela de Martorell, los poetas romanos apuntan a un combate mutuo, con una participación más o menos activa de la mujer. En el Tirant, en cambio, es habitualmente el caballero quien lucha y conquista a la enamorada, que adopta en el acto amoroso un papel pasivo. Siguiendo con el paralelismo de la vida militar, la conquista culmina habitualmente en el triunfo del amante:

E Tirant suplicava l'altesa vostra que li fésseu gràcia de soltar-li lo sagrament perquè pogués obtenir lo victoriós triümfo que desitjava, així com son cosí; e la celsitud vostra no volgué, sinó que restàs gloriosa en la batalla. (cap. 163)

Las alusiones alcanzan al conjunto del léxico de la vida militar. Propercio recomienda los regalos valiosos como armas que deben utilizarse en la conquista amorosa:

estas armas doblegan incluso a las poderosas enclaustradas

(Elegías, III, 13, 9)

También hieren las armas tradicionales —flechas, arco— del dios del Amor: 
No se arma Susa con tantas flechas persas como las que Amor ha clavado en mi pecho.

(Elegías, II, 13, 1-2)

Esta imagen, incorporada a la tradición literaria occidental, es recogida por Martorell en numerosas ocasiones, como en el capítulo en que Tirant se enamora de Carmesina, con la rúbrica Com Tirant fon ferit en lo cor ab una fletxa que li tirà la deessa Venus perquè mirava la filla de l' emperador. (cap. 118)

Otras veces los elegíacos aluden a referencias sexuales directas:

correspondí y dimos rienda suelta a las armas del amor por todo el lecho

(Propercio, Elegías, IV, 8, 88).

Aunque más concretas todavía son las alusiones de Martorell:

En aquest punt Tirant l'hagué acabada de descordar, e al braç la posà sobre lo llit. Com la Princesa se véu en tan estret pas que Tirant despullat s'era mès al seu costat e treballava ab l'artelleria per entrar en lo castell, i ella veent que per força d'armes no el podia defendre, pensà si ab les armes de les dones si el poria fer estalvi (cap. 280)

Martorell se muestra especialmente inclinado a las imágenes militares en la dilatada consumación de los amores de Tirant y Carmesina. El capítulo 436 en que esta se relata, lleva precisamente la rúbrica Com Tirant vencé la batalla e per força d'armes entrà en lo castell, retomando la metáfora que acabamos de comentar. Como es sabido, la Princesa intenta disuadir al protagonista de que utilice con ella la fuerza y se vale para ello también del léxico de la milicia:

no vullau usar de bel-licosa força... Los combats d'amor no es volen molt estrènyer...jQue no deuen tallar les armes d'amor, no han de rompre, no deu tallar l'enamorada llança!

y siguiendo esta línea el narrador nos informa del desenlace:

en poca hora Tirant hagué vençuda la batalla delitosa, e la Princesa reté les armes e abandonà's mostrant-se esmortida.

y como colofón titula el capítulo 438 Com aprés feta la pau Tirant recità a la Princesa tots los seus treballs, e aprés les grans prosperitats que havia hagudes.

El uso de la violencia con la amada que se resiste ya había sido aconsejado por Ovidio en el Ars (I, 670ss) y aparece de forma expresa en los versos del apasionado Propercio:

Pero si, obstinada, te acuestas vestida, en tu vestido rasgado probarás mis manos.

Más aún, si la ira me lleva más lejos, enseñarás a tu madre tus brazos lastimados

(Elegías, II, 15, 17-20) 
La metáfora de la batalla delitosa se repite y amplía en la obra de Martorell más adelante, adaptada al contexto caballeresco de la novela con una identificación expresa del comportamiento de Tirant como caballero y como amante:

E la Reina, aprés que els hagué posats dins la lliça, concordes de la delitosa batalla, se n'anà a dormir confiant que es concordarien que jamés la batalla no vendria a fi. Tirant no dormí en tota aquella nit, como a cavaller valerós, car contemplar-se deu que qui és valerós en lo camp deu ésser valerós en lo llit. (cap. 445)

O con pequeñas variantes en el caso de la emperatriz e Hipòlit cuya batalla, en la que esta dama madura sí tiene un papel activo, es calificada de perillosa:

tocaren-li lo pols e trobaren-lo-hi molt mogut per lo moviment que tenia, que s'esperava entrar en lliça de camp clos amb cavaller jove, e dubtava la perillosa batalla. (cap. 260)

\section{SERVITIUM AMORIS}

Si lo vostre entendre coneixerà jo sia digne de resposta, sia tal e que visca o fenesca prest ma vida car no em trobe dispost sinó en seguir tot ço que per vostra celsitud manat me serà. (cap. 247)

Las palabras de sumisión de Tirant contrastan con la actuación de este caballero fogoso y finalmente decidido a conquistar por la fuerza a la amada, pero se corresponden fielmente al tópico del amante siervo de su dama, tan recurrente en la elegía latina, difundido ampliamente con posterioridad por la poesía trovadoresca. De entre los elegíacos latinos, Tibulo fue quien gustó particularmente de esta imagen:

De esta manera veo me están preparadas servidumbre y dueña, ¡ay de mí, libertad aquella de mis padres, adiós! una servidumbre pero triste se me decreta y estoy aprisionado en cadenas, y jamás al desgraciado sus cadenas afloja Amor.

(Carmina, II, 4, 1-4)

Propercio se refiere en los mismos términos a su relación con su amada Cintia:

Cinco años he sido capaz de ser tu fiel esclavo

(Elegías, III, 25, 3)

o cuando alude a su propio funeral dice:

y haya dos versos: el hombre que ahora yace como el polvo desagradable, ése fue en otro tiempo esclavo de amor

(Elegías, II, 13, 35-36) 
La actitud de humillación y súplica de Tirant respecto a la Princesa se acentúa por la diferencia social entre ambos:

Lo plaer meu és no remetre res a la fortuna, enemiga de mon delit, tota volta creent lo que per l'altesa vostra manat me serà és lo millor. (cap. 243)

Per què us suplic vullau obrir les vostres piadoses orelles als meus tan justs precs, car qui és noble de llinatge e d'obres virtuós, no deu retenir ab si crueldad, qui no és poseïda sinó per males persones. (cap. 290)

Pero Tirant no es en la novela el único amante sumiso que se declara esclavo de amor. En una situación similar se encuentra Hipòlit ante la emperatriz:

com la majestad vostra sia aquella per aquella qui en lo cel és pronosticat jo us dega amar e servir tots los dies de la mia vida (cap. 249)

y reitera un poco más adelante:

E per ço, senyora, vos suplic e us demane de molta gràcia e mercè, que jo no haja més a dir, sinó que em maneu com a ma senyora qualsevulla coses perilloses de ma persona. (cap. 255)

Las palabras de súplica se acompañan a menudo de fórmulas de tratamiento y de gestos del mismo tenor que subrayan la inferioridad del enamorado:

solament vos suplic, agenollat als vostres peus, me façau cert per l'honor vostra com regir-me dec ; (cap. 257)

De entre los caballeros enamorados que aparecen en la novela de Martorell es precisamente Hipòlit quien se muestra particularmente sumiso ante su amante, aspecto que se relaciona con la evidencia de que, en el caso de Hipòlit, su actitud de servicio a la emperatriz no está exenta de intereses particulares:

e li era estat sempre molt obedient en tot lo que per ella li era manat. (cap. 479)

Oïdes per Hipòlit paraules de tanta amor, li besà la mà i la boca e dix que faria tot lo que sa majestat li manava. (cap. 479)

\section{PUELLA DOCTA}

La enamorada se sitúa, como hemos visto, en un plano superior a su amante en la relación amorosa. Es tratada, al igual que en la elegía latina, como la domina frente a su servidor. Comparte, asimismo, otros aspectos con las amadas de los poetas latinos.

En primer lugar, la amada es, por supuesto, bella. Y su belleza se concreta en la descripción de determinadas partes de su cuerpo. Esta es la primera referencia, de un marcado carácter sensual, que tenemos los lectores de Carmesina: 
estava mig descordada mostrant en los pits dues pomes de paradís que crestallines parien, les quals donaren entrada als ulls de Tirant (cap. 118)

Pero la dama en una de sus primeras conversaciones con Tirant ya hace gala, asimismo, de su esmerada educación:

- ¿E com pensau vós — dix la Infanta— que les dones gregues sien de menys valor que les franceses? En esta terra bé sabran entendre lo vostre llatí per escur que el vullau parlar. (cap. 119)

Los poetas latinos, por su parte, se muestran parcos en la descripción física de su amada. Todos resaltan su belleza y su encanto sin aportar demasiados datos concretos. Catulo nos ofrece pocos detalles de Lesbia:

Salud, joven, que no tienes nariz pequeña,

ni pies bonitos, ni ojos oscuros,

ni dedos largos, ni boca seca,

ni lengua demasiado elegante,(...)

¿A ti la provincia te tiene por bonita?

¿A ti se te compara con Lesbia?

¡Oh tiempos sin gusto ni sensibilidad! (Carmina, 43)

Lesbia sí que es hermosa, pues no solamente es la más hermosa en todo, sino también es la única que robó todos los encantos de Venus.

(Carmina, 86, 5-6)

Tibulo prescinde de la descripción de sus amadas y Ovidio se fija en sus rasgos más sensuales:

Cuando quedó erguida sin vestiduras frente a mis ojos, en ninguna parte de su cuerpo encontré defecto alguno: ¡qué hombros!, ¡qué brazos tan hermosos vi y toqué!, ¡cuán a propósito era la forma de sus senos para apretarlos!, ¡qué liso su vientre bajo el terso pecho!, ¡qué anchas y estupendas sus caderas!, ¡qué juvenil su muslo!

(Amores, I, 17-22)

Algo más explícito se muestra Propercio:

Su cabello es rubio, largas sus manos, esbelto todo su cuerpo, y su andar digno es incluso de la hermana de Júpiter

(Elegías, II, 2, 5-6)

No me ha cautivado tanto su rostro, aunque es espléndido (los lirios no son más blancos que mi dueña:

es como la nieve meótica si rivalizara con el bermellón íbero, y como los pétalos de la rosa nadan en pura leche), 
ni su cabello, que cae ordenadamente por su cuello suave, ni sus ojos, dos antorchas que son mis estrellas

(Elegías, II, 3, 9-14)

Y vale la pena contrastar sus versos con la detallada descripción que Martorell presenta de Carmesina:

estava admirat dels seus cabells, qui de rossor resplandien com si fossen madeixes d'or, los quals per eguals parts departien una clenxa de blancor de neu per mig del cap; e estava admirat encara de les celles que paria fossen fetes de pinzell llevades un poc en alt, no tenint molta negror d'espessura de pèls, mas estant ab tota perfecció de natura; mas estava admirat dels ulls, que parien dues esteles rodones relluints com a pedres precioses, no pas girant-los vigorosament, mas refrenats per graciosos esguards, parien que portassen ab si ferma confianza; lo seu nas era prim e afilat e no massa gran ni poc segons la llindesa de la cara, que era d'extrema blancor de roses ab lliris mesclada; los llavis tenia vermells com a coral e les dents molt blanques, menudes e espesses que parien de crestall. E estava més admirat de les mans, que eren d'extrema blancor e carnudes que no s'hi mostrava os negú, ab los dits llargs e afilats, les ungles canonades e encarnades que mostraven portar alquena, no tenint en res defalt de natura. (cap. 119)

La presencia de elementos comunes en ambos textos es evidente: el cabello rubio, los lirios, la rosa, la nieve, el bermellón, los ojos como estrellas, las manos largas. Pese al mayor desarrollo del texto de Martorell, es palpable el fondo de la tradición literaria de origen clásico, incorporada ya a los modelos que inspiran la novela de Martorell, que recoge los rasgos físicos asociados al patrón de belleza de la dama amada.

Pero Propercio continúa:

me ha cautivado su elegancia en el baile, servido ya el vino, como cuando Ariadna dirigía las danzas de las Ménades; y me ha cautivado cuando tantea versos en ritmo eolio, tan experta en tañer la lira como Aganipe, y cuando compara sus escritos con la antigua Corina, cuyos versos piensa que ninguna otra puede igualar a los suyos.

(Elegías, II, 3, 17-22)

y subraya su idea de la amada como diosa, la puella divina:

Los dioses te otorgaron estos dones celestiales, no vayas a creer que te los dio tu madre. No, no proceden tales dones de un parto humano: diez meses no han engendrado esos bienes.

Tú has nacido como la única gloria de las jóvenes romanas: 
serás la primera joven romana en acostarte con Júpiter, y no siempre compartirás con nosotros los lechos humanos; después de Helena, la belleza en ti vuelve por segunda vez a la tierra.

$$
\text { (Elegías, II, 3, 25-32) }
$$

que recuerda lejanamente al enamorado Tirant en diversos pasajes de la novela:

¡Tanta bellea, virtut e gràcia ab tanta magnitud de llinatge, ésser aterrada e posada en tan gran decaïment! E si a mi era lícit de jo recitar les perfeccions e grans singularitats que la senyora Princesa posseeix, la qual jo ame e desitge servir, a una deessa la poria acomparar. (cap. 178)

Sobre los seus daurats cabells, una manyosa tota plena de batents d'or e esmaltats, que paria la sua cara que fos d'una deessa. (cap. 450)

La idea se repite asimismo en la novela en clave cristiana:

e deia que ab veritat se podia dir que en tot l'univers món tanta gràcia ni bellea no poguera ésser trobada en un cos mortal, car més paria angèlica que humana. (cap. 463)

Esta amada se muestra a menudo cruel y altiva con su amante. Propercio reprocha a Cintia su dureza:

Y, aunque ella aguante más que la roca de Sicilia y sea más dura que el hierro de los cálibes

$$
\text { (Elegías, I, 16, 29-30) }
$$

de la misma manera que lo hace Hipòlit con Carmesina:

no siau tan dura en amar aquell qui us desitja tostemps servir e us ama en extrem (cap. 252)

Sin embargo, de los aspectos subrayados son quizás la cultura y el refinamiento los rasgos más sobresalientes de las amadas de la elegía latina:

No soy yo un admirador tan grande de un cuerpo hermoso ni si una mujer se ufana de ilustres antepasados: que mi placer sea leer en el regazo de una joven culta

(Propercio, Elegías, II, 13, 9-11)

Que de mí alaben tan sólo haber agradado a mi culta amada

$$
\text { (Elegías, I, 7, 11) }
$$

A este respecto, es interesante recordar las alusiones de la emperatriz a la cultura de su hija cuando se excusa por su débil argumentación, per jo no haver 
estudiat les arts liberals com ma filla (cap. 182), así como las observaciones del narrador sobre los conocimientos de Carmesina:

era senyora de noble enteniment e discreció, en lo passat temps havia après de molts llenguatges per la pràctica dels estrangers qui per la causa de la guerra eren venguts en la cort de la majestat de l'Emperador, pare seu, e molt més que sabia parlar la llengua llatina per haver après de gramàtica e poesia (cap. 463);

O las curiosas instrucciones del fraile en el sermón después de las bodas de Diafebus y Estefanía sobre las condiciones que deben reunir las doncellas, cuando afirma, por delante de las obligaciones religiosas o morales, Lo primer és que sàpien llegir (cap. 221).

También resultan interesantes las escenas de fiestas y banquetes. De la emperatriz se nos dice:

Lo rei de Sicília suplicà a l'Emperadriu que li fes gràcia de dansar ab ell, e la virtuosa senyora li respòs que gran temps havia que deixada s'era, mas que ho faria per contentar-lo. E dansaren los dos moltes danses, car l'Emperadriu era estada en son temps molt agraciada e dansadora singular. (cap. 450)

No obstante, en muchos otros aspectos difieren las amadas del Tirant de las de los elegíacos latinos. Los condicionamientos sociales y religiosos propios de una época diferente influyen en el comportamiento de las damas frente al amor. Las relaciones de la pareja protagonista, como las de Diafebus y Estefanía, tienen como objetivo final el matrimonio, compromiso que se exige al caballero antes de la consumación total de las relaciones. Carmesina, como Estefanía, se muestra como una joven con determinación pero apela constantemente a su honor y fama como justificación para no acceder a las peticiones de su enamorado. Nada parecido encontramos en la elegía latina. Aquí la amada es una mujer a menudo casada o en una situación irregular, que utiliza deliberadamente su encanto para seducir a sus diversos amantes. Carmesina, en cambio, posee una belleza sensual pero inocente y la infidelidad que le atribuye erróneamente Tirant no es más que una maquinación sin fundamento de su rival amorosa. Muy diferente, por cierto, es la situación de Hipòlit y la emperatriz. ${ }^{4}$

${ }^{4}$ La trama de Hipòlit y la Emperatriz se ha puesto en relación, asimismo, con el ciclo artúrico, considerando las reproducciones textuales de obras artúricas localizadas en el Tirant (BUTINYÀ, 1990). En este caso, evidentemente, no cabe otra posibilidad que interpretar el adulterio de los amantes como una parodia de la historia del caballero Lancelot y la reina Ginebra y su catastrófico desenlace. El desenlace de la novela, en efecto, parece señalar con un punto de amargura hacia el final realista del mundo caballeresco y el triunfo de unos nuevos ideales más prosaicos y tangibles. A diferencia de lo que sucede con Hipólito y la Emperatriz, la Tragèdia de Lançalot, de Mossèn Gras, obra de la cual se ha localizado un fragmento en la novela, se inserta de pleno en la tradición caballeresca y en la línea elegíaca. 


\section{SIGNA AMORIS}

Los poetas elegíacos latinos habían recogido de la poesía griega el motivo del flechazo amoroso y sus efectos físicos en los amantes. Catulo recreaba de esta manera un conocido poema de Safo sobre este asunto:
...en cuanto te
miro, Lesbia, mi garganta queda sin voz, mi lengua se paraliza, sutil llama recorre mis miembros, los dos oídos me zumban con su propio tintineo y una doble noche cubre mis ojos.

(Carmina, 51, 6-12)

Ante la belleza de Carmesina el caballero Tirant experimenta, asimismo, un enamoramiento instantáneo y radical.

Tirant pres llicència de tots e anà-se'n a la posada, entrà-se'n en una cambra e posà lo cap sobre un coixí als peus del llit. No tardà molt que li vengueren a dir si es volia dinar. Dix Tirant que no, que lo cap li dolia. E ell estava ferit d'aquella passió que a molts engana. (cap. 118)

y, a continuación, ante las preguntas de Diafebus por su malestar confiesa:

No vullau turmentar més la mia persona — dix Tirant—qua jamés sentí tan greu mal com lo que ara sent, que em farà venir prest a mort miserable

Los sentimientos que experimentan los amantes se traducen en un malestar físico, uno de los motivos característicos de la elegía latina. Los síntomas de amor en los poetas latinos incluyen delgadez, insomnio, suspiros y lamentos, que revelan el desasosiego de los enamorados. Propercio afirma:

Detesto los sueños que nunca arrancan suspiros

(Elegías, III, 8, 27)

Y Tirant reacciona de esta manera la noche en que conoce a Carmesina:

llança's sobre lo llit pensant en la gran bellea que la Infanta posseïa, e lo seu gest tan agraciat li féu tant augmentar lo seu mal que d'una pena que sentia, llavors ne sentí cent, acompanyat de molts gemecs e sospirs. (cap. 119)

Tirant no pogué menjar. E los altres se pensaven que per lo treball de la mar estava destemprat. E per la molta passió que Tirant tenia, llevà's de taula e posà's dins una cambra acompanyat de molts sospirs (cap.119)

Tampoco la joven escapa a los efectos del amor: 
ella estava mig alienada e posada en fort pensament, que no parlava, e mig fora de record, e la sua angèlica cara mudant de diverses colors, car la femenil fragilitat la havia compresa, que no podia parlar. (cap. 119)

La palidez es otro de los signos que delatan la pasión que consume a los enamorados. Si Ovidio exclamaba en el Ars (I, 729), palleat omnis amans, Propercio confiesa:

ya no te extrañará tanto mi palidez

o por qué yo con todo mi cuerpo no soy nadie.

(Propercio, Elegías, I, 5, 21-22)

Así suplica Estefanía ante Tirant por la ausencia de su amante:

Senyor Tirant, dau-me remei o dau-me la mort e soterrau los meus membres banyats ab les llàgrimes mies enmig del camí per on passarà aquell benaventurat Gran Conestable, e porà dir: «Ací jau aquella qui amar en extrem me solia.» E la pietat mia mereixedora és d'aquest premi, car així tremole com les arestes primes del blat qui són mogudes per lo llebeig suae. La sang fuig de mi, e la natural calor desampara lo meu cor e lo cos. (cap. 176)

Las señales de amor llegan en los personajes del Tirant a una intensidad extrema hasta el punto de provocar con cierta frecuencia desmayos y pérdidas de conciencia:

Com la Princesa fon dins en la sua cambra, pensant en les raons que Tirant li havia dit vengué-li un endolciment al cor de sobres d'amor que li portava, venc en tal punt que fon fora de tot record, e caigué esmortida en terra. (cap. 173)

\section{OMNIA VINCIT AMOR}

Ya desde la poesía griega, Amor se muestra como una divinidad poderosa que domina absolutamente el comportamiento de los enamorados.

Diafebus recuerda las palabras del propio Tirant antes de caer él mismo en las redes del amor:

«¿No teniu vergonya de llevar-vos la llibertat e de posar-la en mans de vostre enemic, qui us lleixa ans perir que haver-vos mercè?» faent de tots una gran burla. Emperò jo veig que ell és vengut a caure en lo llaç en lo qual humana força no basta a resistir. (cap. 118)

Aunque, a continuación, compadecido de su estado, le explica:

E encara que vos aparega dura cosa e estranya ésser subjugat al jou d'amor, podeu verdaderament creure que no és en potència de negú poder-hi resistir. (cap.119) 
Maragdina requiere de amores en vano al caballero argumentando:

¿E no saps tu bé que amor és la pus fort cosa del món, que als savis fa tornar folls e als vells fa tornar jóvens, als rics fa tornar pobres, als avars fa tornar liberals, als trists fa tornar alegres e rients, e als alegres fa tornar trists e plens de pensaments? (cap. 331)

La pasión amorosa, siguiendo la tradición de la poesía erótica, se presenta en la elegía latina como un fuego que inflama a los amantes. Propercio recuerda a su amigo Galo:

Yo no pude impedir vuestros abrazos:

tan grande era la loca pasión que os abrasaba

(Elegías, I, 13, 19-20)

Catulo hace confesar a Acmé ante su amado Septimio:

arde en mis tiernas entrañas

un fuego mucho mayor y más apasionado

(Carmina, 45, 15-16)

Y Carmesina se pregunta cuando declara su amor a Tirant:

¿qui és que puga amagar lo foc que per la sua gran flama fum no n'ixca? (cap. 175)

El amor aparece también con frecuencia como una enfermedad que aqueja a los amantes, enfermedad para la que no existe remedio. Si Catulo suplica a los dioses eripite hanc pestem (Carmina, 76, 20), Propercio se dirige a Baco, tu vitium ex animo dilue, Bacche, meo, (Elegías, III, 17,6) y apela a sus amigos, quaerite non sani pectoris auxilia, (Elegías, I, 1, 26). estado:

En la novela de Martorell, Diafebus interroga a su amigo y se interesa por su

Capità Senyor, prec-vos per amor mia que em digau lo vostre mal quin és, car si per mi vos porà ésser donat algun remei ho faré $a b$ molt bona voluntad. (cap. 118)

Ante lo que Tirant se excusa:

Cosí meu —dix Tirant—, lo meu mal a present no fretura vós saber-lo; e jo no tinc altre mal sino de l'aire de la mar qui m'ha tot comprès.

Esta pasión poderosa provoca el furor amoris, la locura de amor, imagen especialmente cultivada por Catulo - que se califica a sí mismo como loco Catulo, (Carmina , 7, 10) - o por el apasionado Propercio, que experimenta el amante incapaz de controlar sus sentimientos: 
Y ya hace un año que no me deja esta loca pasión, mientras se me obliga a tener los dioses contra mí

(Elegías, I, 1, 7-8)

ante la que previene a su amigo Galo o le desea suerte en el amor:

Que tengas suerte en esta locura que te llega por primera vez

(Elegías, I, 13, 35)

tal como hace Diafebus con Tirant:

Bé sou folls tots aquells qui amau (cap. 118)

La locura de amor provoca el cautiverio del amante prisionero de su pasión. Tirant confiesa abiertamente a la Princesa:

Jo só catiu e sotsmès, però catiu no es deu clamar de sa senyora. (cap. 171)

y a su amigo Diafebus:

Lo meu bon germà, ¿quines noves me portau de la que és en virtuts complida e té la mia ànima encativada? (cap. 119)

y Diafebus besa a Carmesina de parte de su enamorado cuando vuelve a Constantinopla con los cautivos enemigos:

Aquesta besada és d'aquell que la celsitud vostra ha condemnat en més fort presó que no són aquests que jo ací he portats. (cap. 145)

Por su parte, Propercio nos describe cómo es capturado por un grupo de Amorcillos, al servicio de su amada:

unos llevaban pequeñas antorchas, otros saetas, e incluso

algunos me pareció que se disponían a encadenarme.

Pero estaban desnudos, y uno de ellos, más descarado,

«Cogedle, dijo, ya lo conocéis bien.

Este es el que una mujer airada ha puesto en nuestras manos»;

habló, y ya tenía yo un lazo echado al cuello.

(Elegías, II, 29, 5-10)

y alude de forma frecuente al cautiverio que impone el amor:

Todo lo ha sepultado tu amor, y ninguna mujer después de ti ha puesto dulces cadenas sobre mi cuello

(Elegías, III, 15, 9-10) 
Esta relación apasionada de los amantes les lleva a establecer entre ellos un foedus amoris, un pacto de amor inviolable:

Me prometes, vida mía, que este amor nuestro será feliz y eterno entre nosotros.

¡Dioses poderosos, haced que sus promesas sean verdaderas

y que sus palabras sean sinceras y de corazón, para que podamos mantener durante toda la vida este pacto eterno de sagrada relación!

(CAtulo, Carmina, 109)

Este pacto se sella simbólicamente con un juramento de amor eterno, el sacramentum amoris, que exige a los amantes la fides, la lealtad. La idea se recoge en las solemnes palabras que Tirant dirige a su enamorada en su juramento de matrimonio:

per ço que faç consemblant sagrament d'ésser-vos lleal e verdader e no oblidarvos per neguna altra qui en lo món sia (cap. 272)

Muchos otros motivos amatorios característicos de la elegía erótica latina pueblan las páginas del Tirant. El lamento dolorido que define a este género poético, la visión del amor como fuente de felicidad y dicha, pero fundamentalmente de sufrimiento. La noche como momento para el placer amoroso que se trunca al alba, el amante rechazado, la presencia de la intermediaria y, en este caso, auténtica praeceptor amoris de los inexpertos amantes, la condena del amante avaro, incluso un tema típicamente properciano como la conjunción del amor y la muerte, están, asimismo, presentes en la novela del escritor valenciano ${ }^{5}$.

El análisis pormenorizado de los motivos amatorios en el Tirant nos lleva, pues, a concluir que, si bien no podemos hablar de una influencia directa, salvo en el caso de Ovidio, sí que podemos afirmar que en la novela de Martorell se detectan numerosos elementos característicos de la elegía latina. Este engarce con la tradición literaria clásica se produce por una doble vía: por una parte, la cultura clásica transmitida de forma más o menos consciente a lo largo de la época medieval, con sus preferencias por diversos autores, en especial, por las obras amatorias de Ovidio; por otra, es el resultado de una nueva sensibilidad, la del Humanismo y la recuperación de los textos clásicos, que supone un cambio en la ideología y en las preferencias estéticas de los escritores del momento.

Los préstamos documentados en el Tirant de las Heroidas en su traducción catalana medieval, constituyen el punto de contacto más directo de Martorell con la elegía latina. La presencia de Boccaccio, Corella y otros autores de su época (PUJOL, 2002), que habían imitado la obra sentimental de Ovidio en lengua vul-

${ }^{5} \mathrm{Ni}$ siquiera está ausente el elemento mitológico, habitual en la elegía latina. El propio Tirant es comparado o directamente identificado en varias ocasiones (vid. cap. 107, cap. 154) con el troyano Héctor, paradigma de héroe guerrero pero también de amante y marido devoto. 
gar, es otra vía de entrada indirecta del elemento amoroso elegíaco presente en toda la novela. Todo ello hace de Martorell un ejemplo de los gustos literarios de este período y de la absorción y reinterpretación de los autores clásicos a través fundamentalmente de las traducciones.

Como hemos visto, el amor constituye uno de los elementos básicos de la novela de Martorell, si no el más importante. Este componente amoroso adopta a lo largo de la extensa narración del Tirant tonos diferentes. La sensualidad, el humor y el desenfado remiten directamente al tono de gran parte de la obra amatoria de Ovidio. El sufrimiento amoroso, el lamento apasionado, la pena de amor, el dolor de la ausencia, _ presentes también en los versos de Ovidio y consustanciales a la elegía latina-, cobran importancia en la novela y completan el panorama sentimental del Tirant.

El análisis detallado de los principales motivos amatorios de la elegía latina corrobora su presencia e importancia en la novela de Martorell, adaptados a los moldes de un género distinto, la novela, con una expresión más mediatizada de los sentimientos y una gran relevancia del elemento caballeresco, desfigurada en algunos momentos, asimismo, por los condicionamientos que impone un período histórico muy diferente.

\section{BIBLIOGRAFÍA}

ALPERA, LL. (1987): «La concepció de l'amor al "Tirant lo Blanc"», Estudis de literatura catalana al País Valencià, Alicante: Universidad de Alicante.

BADIA, L. (1993): «El Tirant en la tardor medieval catalana». En Actes del Simposion Tirant lo Blanc (pp. 35-100). Barcelona: Quaderns Crema.

ButinYÀ, J. (1990): «Una nova font del Tirant lo Blanc». Revista de Filología Románica. 7, 191-196.

CACHo Blecua, J. M. (1993): El amor en el Tirant lo Blanc: Hipòlit y la emperadriu. En Actes del Simposion Tirant lo Blanc (pp. 133-170). Barcelona: Quaderns Crema.

Catulo, C. V. (1988): Poesías, Madrid: Alianza.

CuRTius, E. R. (1955): Literatura europea y Edad Media latina, Méjico: FCE.

GRAs, Mossèn (1984): Tragèdia de Lançalot, Barcelona: Quaderns Crema (ed. M. de Riquer).

HAUF, A. (1993): «Tres cartes d'amor: contribució a l'estudi del gènere epistolar en el Tirant lo Blanch.» En Actes del Simposion Tirant lo Blanc (pp. 379-410). Barcelona: Quaderns Crema.

MARTORell, J. (1983): Tirant lo Blanc. Barcelona: Ed. 62 (MOLC).

Ovidio, P. (1989): Amores, Arte de amar. Madrid: Gredos.

OvidIO, P. (1986): Heroidas. Madrid: CSIC.

PAREDES, J. et alii, (1995): Estudios sobre el «Tirant lo Blanc». Granada: Universidad de Granada. 
Propercio, S. (1989): Elegías, Madrid: Gredos.

Pujol, J. (2002): La memoria literària de Joanot Martorell. Models i escriptura en el Tirant lo Blanc. Montserrat: Publicacions de l'Abadia de Montserrat.

RiQuer, M. (1990): Aproximació al Tirant lo Blanc. Barcelona: Quaderns Crema.

RiQuer, M.(1992): Tirant lo Blanc, novela de historia y de ficción. Barcelona: Sirmio.

TiBulo, (1983): Carmina, Barcelona: Bosch. 